\title{
A New Concept for Melatonin Deficit: On Pineal Calcification and Melatonin Excretion
}

\author{
Dieter Kunz, M.D., Stephan Schmitz, M.D., Richard Mahlberg, M.D., Anabelle Mohr, \\ Christiane Stöter, Karl-Jürgen Wolf, M.D., and Werner Martin Herrmann, M.D.
}

Even though exogenous melatonin has proven to influence sleep and circadian parameters, low endogenous melatonin is not related to sleep disturbances, nor does it predict response to melatonin replacement therapy. In this manuscript, we present a new concept towards a definition of a melatonin deficit. The purpose of the study was to introduce a marker for an intra-individual decrease in melatonin production. Therefore, we developed a method to quantify the degree of pineal calcification (DOC) using cranial computed tomography. Combining pineal DOC with the organs's size, we estimated the uncalcified pineal gland volume. This estimation was positively and significantly associated with 6-sulfatoxymelatonin
(aMT6s), collected over 24 hours in urine, in 26 subjects. Data yielded evidence that the decline in aMT6s excretion with age can be sufficiently explained by an increased pineal calcification. These results suggest that DOC might be useful as an indicator of an intra-individual, decreased capability of the pineal gland to produce melatonin. DOC might prove to be a response-marker for melatonin replacement therapy and a vulnerability marker of the circadian timing system. [Neuropsychopharmacology 21:765-772, 1999] (C) 1999 American College of Neuropsychopharmacology. Published by Elsevier Science Inc.
KEY WORDS: Calcification; Circadian timing system; Melatonin; Pineal gland; Sleep

In mammals, the circadian timing system has proven to be involved in the daily variation of almost any physiological and psychological variable evaluated so far (Weitzman et al. 1978; Wirz-Justice 1987; Johnson et al. 1992; Dijk and Czeisler 1995; Boivin et al. 1997). The rhythm of the circadian pacemaker comprised in the nuclei suprachiasmatici (SCN) becomes entrained to the environmental 24hour rhythm, predominantly by two zeitgebers, light and melatonin (Dawson and Armstrong 1996).

From the Department of Psychiatry (DK, RM, AM, CS, WMH) and Department of Radiology (SS, K-JW) Freie Universität Berlin, Berlin, Germany, and Department of Psychiatry, Medizinische Universität zu Lübeck (DK), Lübeck, Germany.

Address correspondence to: Dr. D. Kunz, Department of Psychiatry, Medizinische Universität zu Lübeck, Ratzeburger Allee 160, 23538 Lübeck, Germany.

Received November 2, 1998; revised March 31, 1999; accepted June 7, 1999.
Melatonin influences the circadian phase in humans inversely compared to light. In particular, this drug delays circadian rhythms when administered in the morning and advances them when administered in the afternoon or early evening according to a phase response curve (PRC), which is nearly opposite in phase to the PRC's for light exposure (Lewy et al. 1992). Melatonin has proven to exert a chronobiotic mode of action (Dawson and Armstrong 1996) by its ability to facilitate the post-flight adaptation to jet-lag (Arendt et al. 1986), to phase advance the sleep of patients suffering from a phase-delay syndrome (Dahlitz et al. 1991; Tzischinsky et al. 1993), and to re-entrain the sleep-wake cycle of patients with a non-24-hour rhythm, such as in the blind, to the environmental light-dark cycle (Arendt et al. 1988; Lapierre and Dumont 1995; McArthur et al. 1996).

However, in only one of the clinical studies (Haimov et al. 1995), in which exogenous melatonin proved usefulness, did low endogenous melatonin excretion predict response (Garfinkel et al. 1995; Hughes et al. 1998; 
Lushington et al. 1998; Youngstedt et al. 1998). Furthermore, normative data as to the amount of melatonin secretion demonstrate a huge inter-individual variability in humans (Dawson et al. 1992; Bergiannaki et al. 1995; Smith et al. 1997). Thus, existing normative data on melatonin excretion in a "healthy population" might only be considered normal in the sense that they are representative for the normal scatter. But since there is yet no pathology that can be attributed to either high or low melatonin levels, "normative" in this context may not necessarily indicate being healthy. The question arises, does a melatonin deficit or a hypopinealism exist at all?

In a previously reported pilot-study we showed that the degree of pineal calcification (DOC) correlated positively to the incidence of chronic daytime tiredness as well as the subjective perception of sleep disturbances (Kunz et al. 1998). The basic assumption in that study was the hypothesis that an increasing degree of pineal calcification, such as with progressing age, would consecutively lead to decreasing melatonin secretion and thereby contribute to an instability of the circadian timing system, including circadian driven components of the sleep-wake cycle, such as circadian sleep propensity and continuity (Dijk and Cajochen 1997; Dijk and Czeisler 1995).

Even though this hypothesis seems to be plausible, it is not in agreement with the literature. It is generally stated that no correlation can be demonstrated between the occurrence of pineal calcification and a reduced melatonin production (Arendt 1995). But, the two studies frequently cited in that context used predominantly skull X-ray, which provides only little information on the quantity of calcification-density and no information about the size of the remaining non-calcified tissue (Bojkowski and Arendt 1990; Commentz et al. 1986).

The adult shape and size of the pineal gland are, presumably genetically, determined early in life and reach their final stage around the first year of life (Wetterberg et al. 1983; Schmidt et al. 1995). The weight and dimensions are highly variable - up to a 20-fold inter-individual variance (Vollrath 1981; Hasegawa et al. 1987; Bhatnagar 1990; Schmidt et al. 1995). Therefore, the notion of an "average-size" is not adequate. Since most of the pineal tissue consists of melatonin producing pinealocytes (Reiter 1981), the high inter-individual variability as to the amount of melatonin secretion may easily be explained by the variability of the amount of (uncalcified) pineal tissue. In addition, since the size of the pineal calcification does not give any information on the remaining active pineal tissue, it is not surprising that the size of pineal calcification itself is not negatively associated to melatonin excretion.

The presented study was aimed at establishing a relationship between melatonin secretion and the size of uncalcified pineal volume.

\section{METHODS}

\section{Study Population}

The study population of 26 individuals consisted of 23 , otherwise healthy patients, who had contacted our outpatient clinic for sleep-related complaints, and three healthy subjects without sleep-related problems (16 female, 10 male; mean-age 44 years, SD: 15; range 17-72 years). Diagnoses according to ICSD-criteria (International Classification of Sleep Disorders) were: healthy $(n=3)$, sleep state misperception $(n=4)$, idiopathic insomnia $(n=7)$, psychophysiological insomnia $(n=4)$, and restless legs syndrome and/or periodic limb movement disorder (RLS/PLMD) $(n=8)$. Whereas 23 subjects were completely free of medication, three subjects had been taking thyroxin for years because of hypothyroidism.

Extensive examinations had to show no evidence of a neurologic, psychiatric or other somatic disease in any of the included subjects. There had to be no evidence of drug or alcohol abuse. All participants were instructed to abstain from alcohol consumption and over-thecounter medications during all study procedures. Computer Tomography (CT) - scans in all subjects had to be considered as revealing no pathological findings. Performed polysomnograpy (PSG) had to rule out any other diagnosis except for primary insomnia or RLS and/or PLMD. Patients, in whom diagnosis was RLS/ PLMD, underwent specific evaluation. Patients were only included when the disorder was considered to be idiopathic.

Special care was taken that subjects did not take any substances which are known to interfere with melatonin production and/or secretion, but which, among the general population, are sometimes not considered to be "medication," e.g., with respect to sleep: benzodiazepines (McIntyre et al. 1988), antidepressants (Skene et al. 1994), beta-blockers (Cowen et al. 1985), and with respect to pain: anti-inflammatory drugs (Surrall et al. 1987; Murphy et al. 1994). Drugscreening in urine included benzodiazepines, barbiturates, cannabinoids, amphetamines, cocain and opiates.

The subjects provided their written informed consent. The experimental protocol was approved by the Ethics Committee of the Freie Universität Berlin.

\section{Computed Tomography and Image Analysis}

In order to estimate pineal volume and DOC, cranial CTs were performed on a Siemens Somatom DRG or DRH in all subjects with the pineal gland covered by 4-millimeter thick, adjacent slices. The evaluation of the imaging data was performed in duplicate in a blinded fashion. The pineal gland was outlined using the image analysis function provided by the CT-machine, thus 
providing the area of the organ in square centimeters. This analysis was performed on all slices on which the organ, or parts of it, were displayed. In the case that the pineal gland was represented in more than one slice, the area values of the individual region of interest (ROI) were added to yield the total organ area.

An automatic image analysis of this ROI provided the maximum attenuation, or density, in Hounsfield Units (HU). This maximum organ density was grouped on a 5-category scale: $0-50 \mathrm{HU}=0 ; 51-150 \mathrm{HU}=1$; $151-250 \mathrm{HU}=2 ; 251-350 \mathrm{HU}=3 ; 351-1000 \mathrm{HU}=4$. Within the gland, parts were defined as calcified and uncalcified by visual inspection. Thus, the defined calcified portion was related to the whole organ area, and its relative portion estimated on a 4-category scale: $0-24 \%=$ $0 ; 25-49 \%=1 ; 50-74 \%=2 ; 75-100 \%=3$.

The imaging data was combined to a score of calcified pineal volume by adding the scale values of maximum organ density and the scale-values of calcified organ portion. This resulted in a scale from 0 to 7 . By dividing the scale-value of calcification by 7 (scale maximum), it is possible to obtain the degree of calcification (DOC). This definition of DOC is a slightly modified version of the previously introduced method (Kunz et al. 1998). Here, DOC $0 / 7$ represents an organ with no calcification, and DOC $7 / 7$ a completely calcified pineal gland of high density. In this respect, DOC represents an estimation of the relation between calcified and total size of pineal tissue. For example: maximal density: 285 HU, calcified portion, $60 \%: 3+2=$ DOC 5 .

In order to estimate the calcified and uncalcified pineal volume, the DOC was then related to the calculated area of the pineal in two ways: firstly, by multiplication of DOC with the organ area in order to estimate the calcified, presumably inactive pineal tissue (e.g., area: $0.75 \mathrm{~cm}^{2}$, DOC 3/7: $0.75 \times 3 / 7=0.321$ calcified tissue); secondly, 1 - DOC was multiplied by the organ area in order to estimate the uncalcified, presumably active pineal (e.g., area: $0.75 \mathrm{~cm}^{2}$, DOC 3/7: $0.75 \times(1-$ $3 / 7)=0.429$ uncalcified tissue). Since, in this respect, calcified and uncalcified pineal tissue are partly based on estimated values, they have arbitrary volume units (VU).

\section{Melatonin Measurements}

Besides very few pathological exceptions, in which intestinal enterochromaffin cells contribute to serum melatonin, the only relevant secretion site for melatonin in the human body is the pineal gland (Tetsuo et al. 1982; Arendt 1995). About $80 \%$ of the pineal gland consists of pinealocytes with the main secretory product being melatonin (Karasek 1983; Reiter 1981). About 90\% of secreted melatonin are excreted in urine as 6-sulfatoxymelatonin (aMT6s) with a plasma half-life of 10-45 minutes (Arendt 1995). Thus, measuring a 24-h amount of aMT6s in urine seems to be an appropriate method for a quantitative estimation of the secretory activity of the pineal to produce melatonin (Graham et al. 1998).

The excretion of aMT6s in urine was measured over a 32-hour period under controlled conditions while subjects were stationed on the ward for polysomnographic recording. Subjects were asked to collect urine in five fractions over five consecutive time intervals: 1) $11.00 \mathrm{PM}$ till 07.00 AM; 2) 07.00 AM till 11.00 AM; 3) 11.00 AM till 06.00 PM; 4) 06.00 PM till 11.00 PM; and 5) $11.00 \mathrm{PM}$ till 07.00 AM.

To control for night-to-night variability of aMT6s, two night fractions-during which the largest quantity is excreted-were averaged. In line with literature, night-to-night intra-individual variability was low, not exceeding $15 \%$ in any of the subjects (e.g., Bergiannaki et al. 1995). A 24-h amount of aMT6s was obtained by adding the averaged night-time fraction to the three day-time fractions. All samples were analyzed in duplicate by IBL (Hamburg), using a highly sensitive, competitive ELISA kit (Pfluger and Minder 1996).

\section{Statistical Analysis}

Data were analyzed using Spearman's rho in order to compute the association between aMT6s and the variables age, sex, DOC, uncalcified, calcified, and the total size of the pineal gland. Applying linear regression analysis, the relationship between DOC, the total size, and the approximated uncalcified respectively to the calcified size of the pineal gland to melatonin excretion were quantified. Here, the 24-h amount of aMT6s was the dependent variable. Modelling strategy proceeded by including sex and age simultaneously with either DOC, the uncalcified, calcified and the total size of the pineal gland in the model.

\section{RESULTS}

Descriptive statistics are shown in Table 1. In line with the literature, there was a high inter-individual variability in the size of the organ as well as the total amount of aMT6s excretion. Again, in line with the literature, there was no association between pineal size and age ( $\mathrm{R}$ (correlation coefficient): $-0.096 ; p=.321$ ).

The total size of the pineal gland was significantly and positively associated to aMT6s using Spearman's rho (R: $0.493 ; p=.005)$. However, the positive association between uncalcified pineal tissue and aMT6s yielded the highest correlation among all investigated parameters (R: 0.672; $p<.001$ ).

There was a significant and negative association between aMT6s and age (R: $-0.504 ; p=.004)$, as well as a strong tendency towards a negative association be- 
Table 1. Descriptives

\begin{tabular}{|c|c|c|c|c|c|}
\hline & $\mathbf{N}$ & Minimum & Maximum & Mean & SD \\
\hline Age & 26 & 17 & 72 & 44.42 & 14.7 \\
\hline Pineal size in $\mathrm{cm}^{2}$ & 26 & 0.11 & 1.33 & 0.538 & 0.329 \\
\hline DOC & 26 & 1 & 7 & 4.23 & 1.86 \\
\hline aMT6s in ng/24h & 26 & 2000 & 65000 & 25431 & 16054 \\
\hline Calcified pineal & 26 & 0.018 & 1.146 & 0.317 & 0.279 \\
\hline Uncalcified pineal & 26 & 0.029 & 0.469 & 0.218 & 0.121 \\
\hline
\end{tabular}

tween uncalcified pineal tissue and age, though not significant ( $\mathrm{R}:-0.309 ; p=.062$ ).

Using linear regression models, neither DOC nor the size of calcified pineal tissue were associated with the 24-hour amount of aMT6s in urine (Figure 1). In contrast, the model including age, sex, and the uncalcified pineal tissue (adj $R^{2}$ (adjusted R square): 0.402; F: 6.601; $p=.002$ ) yielded significance (Figure 2).

By determining betacoefficients in the model including sex, age, and total pineal size as predictors for aMT6s, age [b (standard betacoefficient): $-0.470 ; p=.032]$, and pineal size (b: $0.428 ; p=.025)$ both yielded significance. Exchanging uncalcified pineal tissue for total pineal size within the model, uncalcified pineal tissue (b: $0.519 ; p=.005$ ) was highly significant, but age was not (b: $-0.278 ; p=.164$ ).

\section{DISCUSSION}

The presented data confirm various earlier studies. Firstly, the size of pineal calcification is not associated with melatonin secretion (Bojkowski and Arendt 1990; Commentz et al. 1986). This is in line with the lack of association between the size of pineal calcification and pathologies. Secondly, there is no association between pineal size and age (Hasegawa et al. 1987), which confirms the predominant, genetical determination of pineal size (Schmidt et al. 1995; Bhatnagar 1990). Thirdly, there is a negative correlation between age and aMT6s (Sack et al. 1986; Sharma et al. 1989; Humbert and Pevet 1994; Zhdanova et al. 1997; Waldhauser et al. 1988; Myers and Badia 1995).

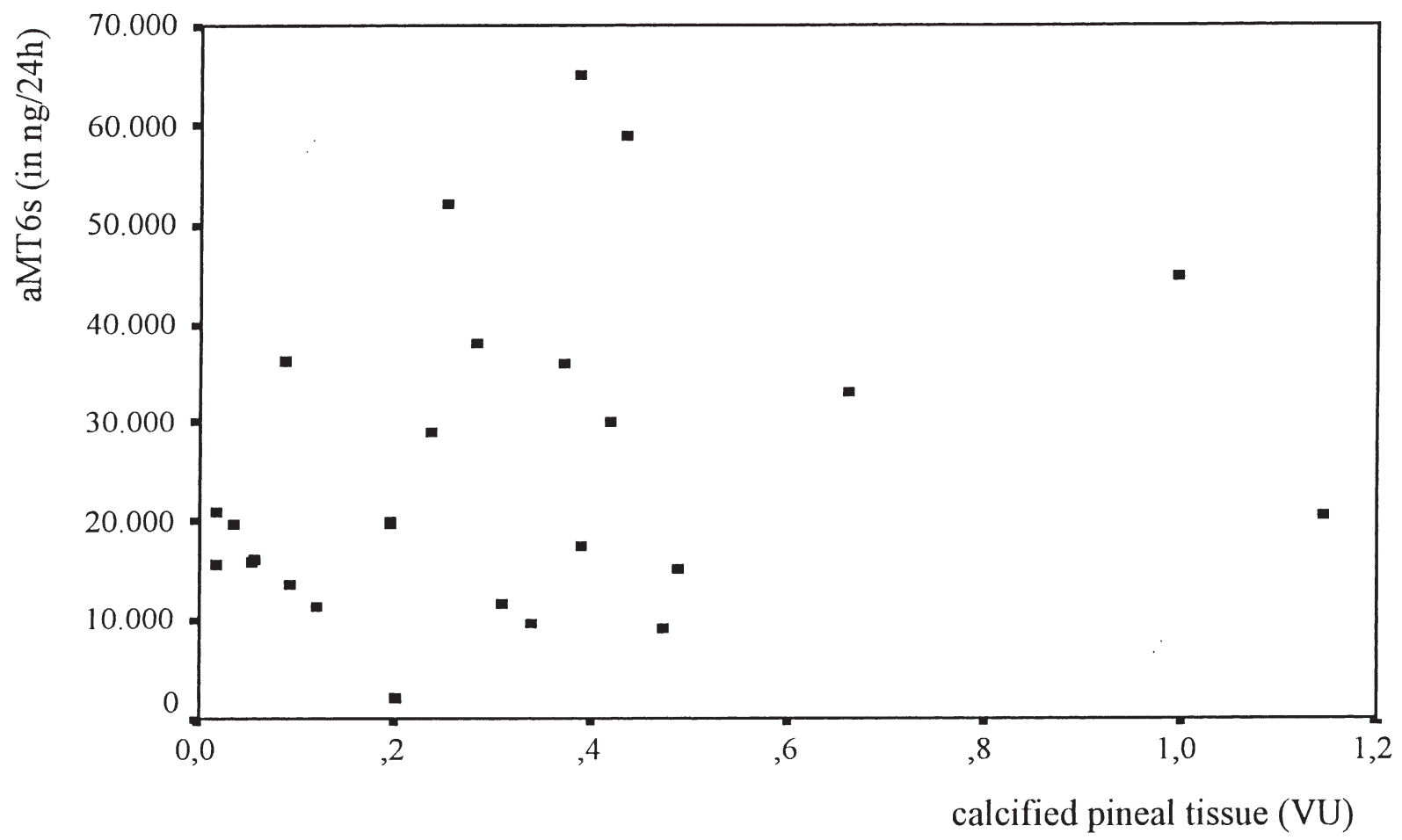

Figure 1. Melatonin excretion vs. calcified pineal. VU: volume units. 


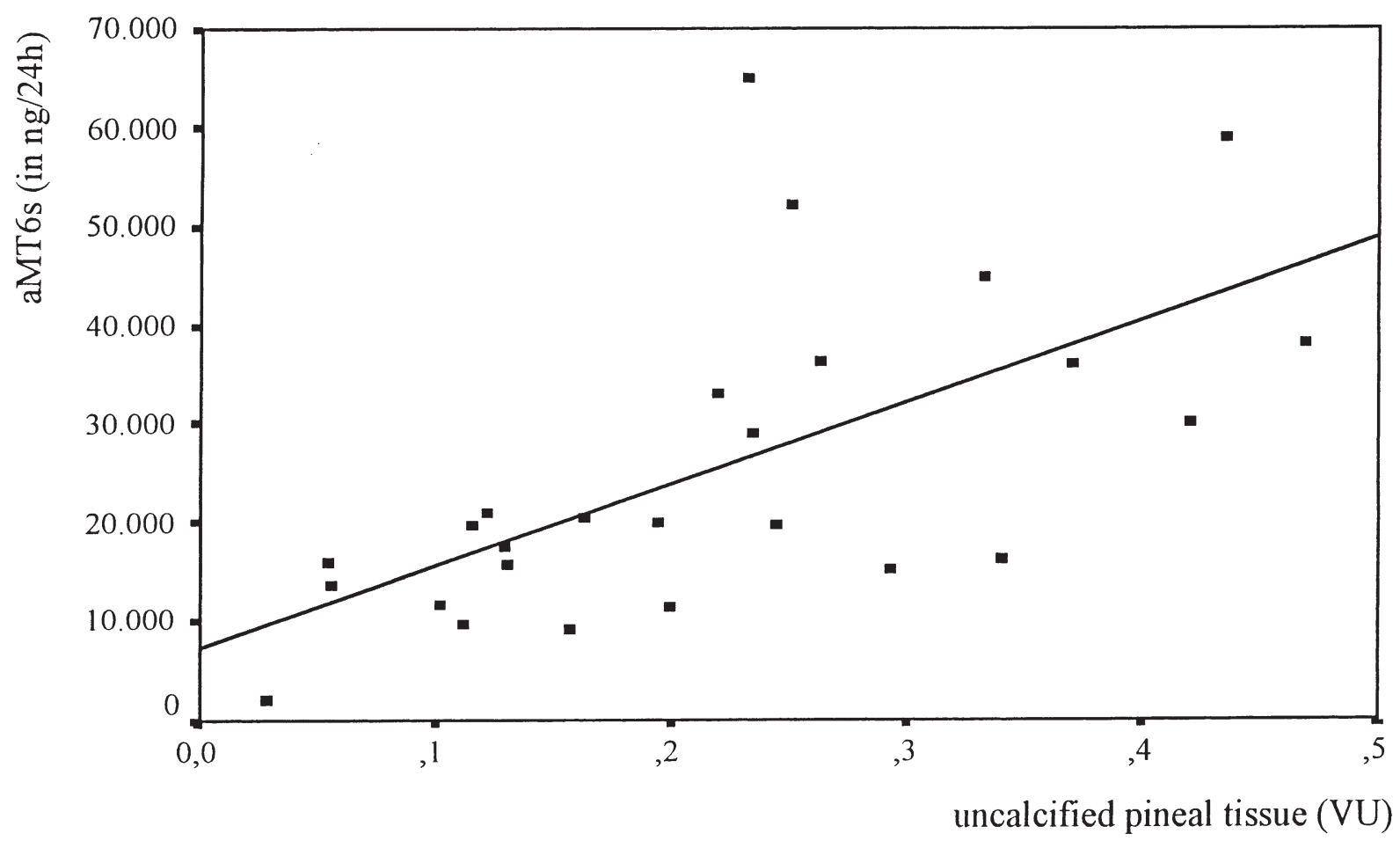

Figure 2. Melatonin excretion vs. uncalcified pineal. Fit line represents regression: dependent aMT6s in ng/24h; predict uncalcified pineal; VU: volume units.

It was shown for the first time in the present study that an approximation of the size of uncalcified pineal tissue, presumably representing active pinealocytes, is significantly and positively associated with the total amount of 24-hour aMT6s excretion in urine. Most interestingly, the well-known negative correlation between age and aMT6s did not persist when data were adjusted to uncalcified pineal tissue. Thus, it is safe to conclude that the decrease of aMT6s excretion with age is predominantly due to increasing pineal calcification and not determined by the aging process per se.

To date, in spite of the structural and histochemical appearance of pineal calcifications being well described, little is known about their biogenesis (Alcolado et al. 1986). Schmid (1993) summarized evidence, further confirmed by Humbert and Pevet (1995), that calcification of pinealocytes results from death or degeneration of the cell itself, thus leading to an overall decrease in pineal activity. Besides, it has been shown that, with age, there is a significant reduction in both melatonin content and the total number of pinealocytes due to a reduction of light pinealocytes, which are known to be functional (Skene et al. 1990; Humbert and Pevet 1995). Occurring simultaneously, there is an increase of dark pinealocytes, which are characterized by an intranuclear deposition of calcium and with many signs of degeneration (Schmid et al. 1994; Humbert and Pevet
1995). With the present data, we may be able to add a link missing so far in the chain of arguments that an increased calcification of the pineal gland represents a decrease in the number of functioning pinealocytes, which results in a decreased ability of the pineal gland to produce melatonin.

What is the clinical impact of our finding? There is overwhelming evidence that melatonin exerts its chronobiotic effects via the SCN (Cassone et al. 1986). On the other hand, there are many hints pointing to the assumption that the SCN`s sensitivity for light and melatonin varies with time (Thompson et al. 1990; Owen and Arendt 1992; Dubocovich et al. 1996) as well as under the influence of various modulators (Medanic and Gillette 1992; Rea et al. 1994; Duncan et al. 1998). It also varies between states (McIntyre et al. 1990), but moreover between individuals (Lewy et al. 1985; McArthur et al. 1996). It has even been shown that melatonin itself influences the sensitivity of its SCN receptors (McArthur et al. 1997).

Given that there is a tremendous, genetically determined, inter-individual variability as to the amount of melatonin excretion, the question arises whether there is an individual threshold for the amount of melatonin required. Moreover, it remains unexplored as to what degree the circadian timing system may adapt to decreased melatonin production as the result of increasing 
pineal calcification. As long as these questions remain unanswered the notion of a "melatonin deficit" lacks a firm conceptual basis. Theoretically, melatonin may not even be necessary at all to the functioning of the circadian timing system, as long as a person stays entrained by well-timed light exposure and/or sufficient strong social zeitgebers. But pinealectomy has proven to increase the SCN's sensitivity to phase-shifting properties of light (Cassone 1992), thereby suggesting that intraindividually decreased melatonin, as indicated by an increased pineal calcification, may be a vulnerability marker with respect to the stability of the circadian timing system.

The authors are unaware of any study on melatonin production that controlled for either the total size of the pineal gland or the size of uncalcified pineal volume. But, since there is a 20 -fold variability in the size of the pineal gland as well as in melatonin production, normative data on melatonin excretion may be useless if the starting point of the intra-individual capability to produce melatonin, as indicated by the total size of the pineal gland, is unknown. We suggest that pineal DOC might prove to be a better marker of an intra-individual pineal deficit, with respect to melatonin secretion than the amount of melatonin secretion itself. It needs to be established whether this deficit marker is associated with pathologies, especially with respect to the circadian timing system in man (Czeisler et al. 1992; Myers and Badia 1995).

Of course, the presented concept is speculative, based on many assumptions, which need confirmation. But, our hypothetical framework might explain why low melatonin secretion does not predict response to melatonin replacement therapy (Garfinkel et al. 1995; Hughes et al. 1998; Lushington et al. 1998; Youngstedt et al. 1998). Some evidence for the validity of our hypothesis comes from the preliminary finding that high pineal DOC is related to disturbances of the sleep-wake cycle (Kunz et al. 1998).

In conclusion, the increasing degree of pineal calcification might be established in the future as an indicator of the intra-individual decrease of the pineal gland's melatonin production. If it will be confirmed that pineal DOC is a vulnerability-marker of disturbances of the sleep-wake cycle and/or the circadian timing system, pineal DOC might also prove to be an indicator of the outcome of melatonin replacement therapy.

\section{ACKNOWLEDGMENTS}

We are grateful to the technical staff of the Sleep Clinic, Department of Psychiatry, Freie Universität Berlin, to Peter Schlattmann for his statistical assistance, to Erik Bes and Bruno Müller-Oerlinghausen for their pre-review, to Carole Bould for her typing and editorial help, and to Amely Tilmann.

\section{REFERENCES}

Alcolado JC, Moore IE, Weller RO (1986): Calcification in the human choroid plexus, meningiomas and pineal gland. Neuropathol Appl Neurobiol 12:235-250

Arendt J (1995): Melatonin and the Mammalian Pineal Gland. Cambridge, University Press

Arendt J, Aldhous M, Marks V (1986): Alleviation of jet lag by melatonin: preliminary results of controlled double blind trial. Br Med J 292:1170

Arendt J, Aldhous M, Wright J (1988): Synchronisation of a disturbed sleep-wake cycle in a blind man by melatonin treatment. Lancet 1:772-773

Bergiannaki JD, Soldatos CR, Paparrigopoulos TJ, Syrengelas M, Stefanis CN (1995): Low and high melatonin excretors among healthy individuals. J Pineal Res 18:159-164

Bhatnagar KP (1990): Comparative Morphology of the Pineal Gland, in Biological Rhythms, Mood Disorder, Light Therapy, and the Pineal Gland. Washington DC, American Psychiatric Press

Boivin DB, Czeisler CA, Dijk DJ, Duffy JF, Folkard S, Minors DS, Totterdell P, Waterhouse JM (1997): Complex interaction of the sleep-wake cycle and circadian phase modulates mood in healthy subjects. Arch Gen Psychiatry 54:145-152

Bojkowski CJ, Arendt J (1990): Factors influencing urinary 6-sulphatoxymelatonin, a major melatonin metabolite, in normal human subjects. Clin Endocrinol 33:435-444

Cassone VM (1992): The pineal gland influences rat circadian activity rhythms in constant light. J Biol Rhythms 7:27-40

Cassone VM, Chesworth MJ, Armstrong SM (1986): Entrainment of rat circadian rhythms by daily injection of melatonin depends upon the hypothalamic suprachiasmatic nuclei. Physiol Behav 36:1111-1121

Commentz JC, Fischer P, Stegner H, Winkler P, Helmke K, Willig RP (1986): Pineal calcification does not affect melatonin production. J Neural Transm 21:481-489

Cowen PJ, Bevan JS, Gosden B, Elliott SA (1985): Treatment with beta-adrenoceptor blockers reduces plasma melatonin concentration. Br J Clin Pharmacol 19:258-260

Czeisler CA, Dumont M, Duffy JF, Steinberg JD, Richardson GS, Brown EN, Sanchez R, Rios CD, Ronda JM (1992): Association of sleep-wake habits in older people with changes in output of circadian pacemaker. Lancet 340:933-936

Dahlitz M, Alvarez B, Vignau J, English J, Arendt J, Parkes JD (1991): Delayed sleep phase syndrome response to melatonin. Lancet 337:1121-1124

Dawson D, Armstrong SM (1996): Chronobiotics-drugs that shift rhythms. Pharmacol Ther 69:15-36

Dawson D, Lushington K, Lack L, Campbell S, Matthews C (1992): The variability in circadian phase and amplitude estimates derived from sequential constant routines. Chronobiol Int 9:362-370

Dijk DJ, Cajochen C (1997): Melatonin and the circadian regulation of sleep initiation, consolidation, structure, and the sleep EEG. J Biol Rhythms 12:627-635 
Dijk DJ, Czeisler CA (1995): Contribution of the circadian pacemaker and the sleep homeostat to sleep propensity, sleep structure, electroencephalographic slow waves, and sleep spindle activity in humans. J Neurosci 15:3526-3538

Dubocovich ML, Benloucif S, Masana MI (1996): Melatonin receptors in the mammalian suprachiasmatic nucleus. Behav Brain Res 73:141-147

Duncan WCJ, Johnson KA, Wehr TA (1998): Decreased sensitivity to light of the photic entrainment pathway during chronic clorgyline and lithium treatments. J Biol Rhythms 13:330-346

Garfinkel D, Laudon M, Nof D, Zisapel N (1995): Improvement of sleep quality in elderly people by controlledrelease melatonin. Lancet 346:541-544

Graham C, Cook MR, Kavet R, Sastre A, Smith DK (1998): Prediction of nocturnal plasma melatonin from morning urinary measures. J Pineal Res 24:230-238

Haimov I, Lavie P, Laudon M, Herer P, Vigder C, Zisapel N (1995): Melatonin replacement therapy of elderly insomniacs. Sleep 18:598-603

Hasegawa A, Ohtsubo K, Mori W (1987): Pineal gland in old age; quantitative and qualitative morphological study of 168 human autopsy cases. Brain Res 409:343-349

Hughes RJ, Sack RL, Lewy AJ (1998): The role of melatonin and circadian phase in age-related sleep-maintenance insomnia: Assessment in a clinical trial of melatonin replacement. Sleep 21:52-68

Humbert W, Pevet P (1994): The decrease of pineal melatonin production with age. Causes and consequences. Ann NY Acad Sci 719:43-63

Humbert W, Pevet P (1995): The pineal gland of the aging rat: Calcium localization and variation in the number of pinealocytes. J Pineal Res 18:32-40

Johnson MP, Duffy JF, Dijk D-J, Ronda JM, Dyal CM, Czeisler CA (1992): Short-term memory, alertness and performance: A reappraisal of their relationship to body temperature. J Sleep Res 1:24-29

Karasek M (1983): Ultrastructure of the mammalian pineal gland: Its comparative and functional aspects. Pineal Res Rev 1:1-48

Kunz D, Bes F, Schlattmann P, Herrmann WM (1998): On pineal calcification and its relation to subjective sleep perception: A hypothesis-driven pilot study. Psychiatry Res 82:187-191

Lapierre O, Dumont M (1995): Melatonin treatment of a non24-hour sleep-wake cycle in a blind retarded child. Biol Psychiatry 38:119-122

Lewy AJ, Ahmed S, Jackson JM, Sack RL (1992): Melatonin shifts human circadian rhythms according to a phaseresponse curve. Chronobiol Int 9:380-392

Lewy AJ, Nurnberger JIJ, Wehr TA, Pack D, Becker LE, Powell RL, Newsome DA (1985): Supersensitivity to light: Possible trait marker for manic-depressive illness. Am J Psychiatry 142:725-727

Lushington K, Lack L, Kennaway DJ, Rogers N, van den Heuvel C, Dawson D (1998): 6-Sulfatoxymelatonin excretion and self-reported sleep in good sleeping controls and 55-80-year-old insomniacs. J Sleep Res 7:75-83

McArthur AJ, Hunt AE, Gillette MU (1997): Melatonin action and signal transduction in the rat suprachiasmatic circadian clock: Activation of protein kinase $\mathrm{C}$ at dusk and dawn. Endocrinology 138:627-634

McArthur AJ, Lewy AJ, Sack RL (1996): Non-24-hour sleepwake syndrome in a sighted man: Circadian rhythm studies and efficacy of melatonin treatment. Sleep 19:544-553

McIntyre IM, Burrows GD, Norman TR (1988): Suppression of plasma melatonin by a single dose of the benzodiazepine alprazolam in humans. Biol Psychiatry 24:108-112

McIntyre IM, Norman TR, Burrows GD, Armstrong SM (1990): Melatonin supersensitivity to dim light in seasonal affective disorder. Lancet 335:488

Medanic M, Gillette MU (1992): Serotonin regulates the phase of the rat suprachiasmatic circadian pacemaker in vitro only during the subjective day. J Physiol 450:629_ 642

Murphy PJ, Badia P, Myers BL, Boecker MR, Wright KPJ (1994): Nonsteroidal anti-inflammatory drugs affect normal sleep patterns in humans. Physiol Behav 55:1063-1066

Myers BL, Badia P (1995): Changes in circadian rhythms and sleep quality with aging: Mechanisms and interventions. Neurosci Biobehav Rev 19:553-571

Owen J, Arendt J (1992): Melatonin suppression in human subjects by bright and dim light in Antarctica: Time and season-dependent effects. Neurosci Lett 137:181-184

Pfluger DH, Minder CE (1996): Effects of exposure to 16.7 $\mathrm{Hz}$ magnetic fields on urinary 6- hydroxymelatonin sulfate excretion of Swiss railway workers. J Pineal Res 21:91-100

Rea MA, Glass JD, Colwell CS (1994): Serotonin modulates photic responses in the hamster suprachiasmatic nuclei. J Neurosci 14:3635-3642

Reiter RJ (1981): The mammalian pineal gland: structure and function. Am J Anat 162:287-313

Sack RL, Lewy AJ, Erb DL, Vollmer WM, Singer CM (1986): Human melatonin production decreases with age. J Pineal Res 3:379-388

Schmid HA (1993): Decreased melatonin biosynthesis, calcium flux, pineal gland calcification and aging: A hypothetical framework. Gerontology 39:189-199

Schmid HA, Requintina PJ, Oxenkrug GF, Sturner W (1994): Calcium, calcification, and melatonin biosynthesis in the human pineal gland: A postmortem study into agerelated factors. J Pineal Res 16:178-183

Schmidt F, Penka B, Trauner M, Reinsperger L, Ranner G, Ebner F, Waldhauser F (1995): Lack of pineal growth during childhood. J Clin Endocrinol Metab 80:12211225

Sharma M, Palacios-Bois J, Schwartz G, Iskandar H, Thakur M, Quirion R, Nair NP (1989): Circadian rhythms of melatonin and cortisol in aging. Biol Psychiatry 25:305-319

Skene DJ, Bojkowski CJ, Arendt J (1994): Comparison of the effects of acute fluvoxamine and desipramine administration on melatonin and cortisol production in humans. Br J Clin Pharmacol 37:181-186

Skene DJ, Vivien-Roels B, Sparks DL, Hunsaker JC, Pevet P, Ravid D, Swaab DF (1990): Daily variation in the concentration of melatonin and 5-methoxytryptophol in the 
human pineal gland: Effect of age and Alzheimer's disease. Brain Res 528:170-174

Smith JS, Elliot JA, Kripke DF (1997): Circadian rhythms of 6-sulphatoxymelatonin in healthy adults. Sleep Res 26:753

Surrall K, Smith JA, Bird H, Okala B, Othman H, Padwick DJ (1987): Effect of ibuprofen and indomethacin on human plasma melatonin. J Pharm Pharmacol 39:840-843

Tetsuo M, Perlow MJ, Mishkin M, Markey SP (1982): Light exposure reduces and pinealectomy virtually stops urinary excretion of 6-hydroxymelatonin by rhesus monkeys. Endocrinology 110:997-1003

Thompson C, Stinson D, Smith A (1990): Seasonal affective disorder and season-dependent abnormalities of melatonin suppression by light. Lancet 336:703-706

Tzischinsky O, Shlitner A, Lavie P (1993): The association between the nocturnal sleep gate and nocturnal onset of urinary 6-sulfatoxymelatonin. J Biol Rhythms 8:199-209

Vollrath L (1981) The pineal organ. In Oksche A, Vollrath L (eds), Handbuch der mikroskopischen Anatomie des Menschen, 7th ed. Berlin, Springer
Waldhauser F, Weiszenbacher G, Tatzer E, Gisinger B, Waldhauser M, Schemper M, Frisch H (1988): Alterations in nocturnal serum melatonin levels in humans with growth and aging. J Clin Endocrinol Metab 66:648652

Weitzman ED, Czeisler CA, Moore-Ede MC (1978): Sleepwake, neuroendocrine and body temperature circadian rhythms under entrained and non-entrained (free-running) conditions in man. Acta Endocrinol 89:25-29

Wetterberg L, Iselius L, Lindsten J (1983): Genetic regulation of melatonin excretion in urine. A preliminary report. Clin Genet 24:399-402

Wirz-Justice A (1987): Circadian rhythms in mammalian neurotransmitter receptors. Prog Neurobiol 29:219-259

Youngstedt SD, Kripke DF, Elliott JA (1998): Melatonin excretion is not related to sleep in the elderly. J Pineal Res 24:142-145

Zhdanova IV, Wurtmann RJ, Balcioglu A, Lynch HJ (1997): Endogenous and exogenous melatonin levels: Age effects. Sleep Res 26:147-149 